\title{
A Relationship Between Cervical Vertebrae Twisting and Cranial Angle in Head and Neck Radiotherapy
}

\author{
TAKAHIRO AOYAMA ${ }^{1,2}$, HIDETOSHI SHIMIZU ${ }^{1}$, KOJI SASAKI $^{3}$, MIO ANDO $^{4}$, NAOKI KANEDA $^{4}$, \\ HIROYUKI TACHIBANA ${ }^{1}$, KOJIRO SUZUKI ${ }^{5}$ and TAKESHI KODAIRA ${ }^{1}$ \\ ${ }^{1}$ Department of Radiation Oncology, Aichi Cancer Centre Hospital, Nagoya, Japan; \\ ${ }^{2}$ Graduate School of Medicine, Aichi Medical University, Nagakute, Japan; \\ ${ }^{3}$ Graduate School of Radiological Technology, \\ Gunma Prefectural College of Health Sciences, Maebashi, Japan; \\ ${ }^{4}$ Department of Radiological Technology, Aichi Medical University Hospital, Nagakute, Japan; \\ ${ }^{5}$ Department of Radiology, Aichi Medical University, Aichi, Japan
}

\begin{abstract}
Background/Aim: Because current image-guided radiotherapy systems can only correct six axes, it is impossible to correct the twisting of cervical vertebrae. The purpose of this study was to clarify the relationship between cervical vertebrae twisting and cranial angle. Materials and Methods: Nineteen patients who underwent intensity-modulated radiation therapy were retrospectively reviewed. Twisting of cervical vertebrae was analysed using planning computed tomography (CT) and megavoltage CT images for image-guided radiotherapy. Results: Although the cranial angle during planning CT was not strongly correlated with twisting (correlation coefficient <0.7), when the patients were divided into two groups by cranial angle, the twisting of the small-angle group was significantly reduced. Specifically, cranial angles of $<25^{\circ}$ significantly and efficiently reduced the twisting of the upper cervical vertebra compared with those of the other groups. Conclusion: Twisting of the upper cervical vertebrae is reduced by using a cranial angle of $<25^{\circ}$ during planning $C T$.
\end{abstract}

Intensity-modulated radiotherapy (IMRT) has made it possible to deliver sufficient doses to tumours, even when they are positioned close to healthy organs $(1,2)$. IMRT is particularly useful in head and neck cancer in close proximity to the organs at risk such as the spinal cord and parotid gland $(3,4)$. Because

This article is freely accessible online.

Correspondence to: Takahiro Aoyama, R.T., MS., Department of Radiation Oncology, Aichi Cancer Centre Hospital, 1-1 Kanokoden, Chikusa-Ku, Nagoya, Aichi, 464-8681, Japan. E-mail: aoyamat@aichi-cc.jp

Key Words: Cervical vertebrae, computed tomography, cranial angle, head and neck radiotherapy, twisting. of the importance of patient positioning in IMRT, image-guided radiotherapy (IGRT) is used for accurate alignment (5). However, even with IGRT, cervical vertebrae are often twisted in three directions [flexion-extension (FE), axial rotation (AR), or lateral bending (LB)] as shown in Figure 1. Because current IGRT systems can only correct six axes (three translations and three rotations), it is impossible to correct the twisting of cervical vertebrae with the IGRT system $(6,7)$. Some reports discuss the development of a twist-correction system $(8,9)$, but this is not yet commercially available. Therefore, in the event of a clinically unacceptable large twisting, re-positioning would be required at the expense of increasing patient burden and reduced throughput. For this reason, it is important to correct twisting before IGRT. A study on the positioning method to prevent twisting of cervical vertebrae is useful; however, to our knowledge, no study has examined patient position to prevent twisting. The only study on the position alignment method to prevent set-up error is from Lam et al. (10), who have reported the translational offsets in the superoinferior, mediolateral, and anteroposterior directions of cervical vertebrae. According to this report, the positional alignment of tucking in the patient's chin increased the set-up error compared to when the chin was not pulled. However, their report only examined translations, not twisting. The effect between twisting of cervical vertebrae and cranial angle has not been investigated. Panjabi et al. have reported that as the twisting of cervical vertebrae for $\mathrm{LB}$ always involves $\mathrm{AR}$ (i.e. motion coupling) (11), to limit LB is possible by restricting AR. In addition, the maximum range of LB angle is only $80^{\circ}$, smaller than the range of $\mathrm{FE}$ angle $\left(135^{\circ}\right)$ and $\mathrm{AR}$ angle $\left(180^{\circ}\right)(12)$. Therefore, it is important to consider the position alignment method to prevent the occurrence of FE and AR. The purpose of this study was to clarify the relationship between cervical vertebrae twisting and cranial angle of planning computed tomography (CT) by evaluating the FE angle and AR angle using megavoltage CT (MVCT) for IGRT. 


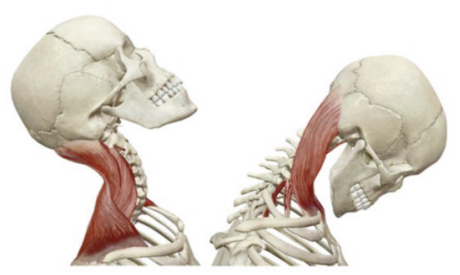

(a) flexion-extension

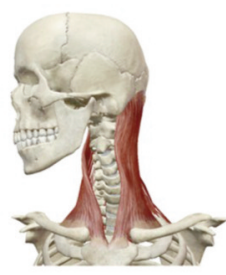

(b) axial rotation

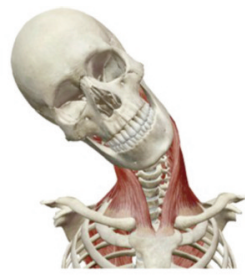

(c) lateral bending

Figure 1. Illustration of the twisting of cervical vertebrae: (a) flexion-extension, (b) axial rotation, and (c) lateral bending.

\section{Materials and Methods}

Cranial angle measurement. The records of 19 patients who underwent IMRT for head and neck cancer at our hospital between April 2015 and February 2017 were retrospectively reviewed. This study was approved by our ethics committee (No. 2017-1-046). During treatment, each patient lay on Silverman's headrest type B or C (CIVCO, Kalona, IA, USA) and was immobilised using a Type $\mathrm{S}$ head and neck and shoulder thermoplastic mask (CIVCO). The angle between a line connecting the lateral canthus and the centre of the external acoustic meatus (i.e. orbitomeatal base line) and a vertical line was defined as the cranial angle (Figure 2). For all 19 patients, the cranial angle during planning CT was measured. All patients underwent daily MVCT for IGRT using a TomoTherapy Hi$\mathrm{Art}^{\mathrm{TM}}$ system (Accuray, Inc., Madison, WI, USA).

Measurement of twisting of cervical vertebrae. Twisting of cervical vertebrae was analysed using planning CT and MVCT images. Data analysis was conducted in four steps using MIM Maestro version 6.6.9 (MIM Software Inc., Cleveland, OH, USA). The first step involved rigid image registration of planning CT and MVCT images with reference to the fourth cervical vertebra as shown in Figure 3. Second, the line connecting the anterior centre $\left(A_{n}\right)$ to the posterior centre $\left(P_{n}\right)$ of the lower end of the cervical vertebra was defined as a reference line for measuring twisting (Figure 4). Third, the angle between the reference line $\left(A_{n}-P_{n}\right)$ in planning CT images and the reference line $\left(A_{n}^{\prime}-P_{n}^{\prime}\right)$ in MVCT images were defined as $\theta$ (Figure 4). Finally, the absolute values of the angles by projecting $\theta$ to the $\mathrm{YZ}$ and $\mathrm{XZ}$ cross-sections were defined as FE angle and AR angle of the $n$th cervical vertebra, respectively. These four analytical procedures were performed for $\mathrm{C} 1, \mathrm{C} 2, \mathrm{C} 3, \mathrm{C} 5, \mathrm{C} 6$, and $\mathrm{C} 7$. Although multiple IGRT images are more appropriate for assessing positional variability (13), patients often lose weight rapidly one week after the start of irradiation in head and neck radiotherapy (14). Therefore, in this study, three MVCT images (fraction numbers 1, 2, and 3) from the start of irradiation were used. In addition, the average value \pm standard deviation of the FE angle and the $\mathrm{AR}$ angle in $\mathrm{C} 1, \mathrm{C} 2, \mathrm{C} 3, \mathrm{C} 5, \mathrm{C} 6$, and $\mathrm{C} 7$ were calculated.

Analysis of the relationship between the cranial angle and twisting of cervical vertebrae. All patients were divided into two groups to compare the relationship between twisting of the cervical vertebrae and the cranial angle. The cranial angles used for grouping were independently $20^{\circ}, 25^{\circ}, 30^{\circ}$, and $35^{\circ}$. The group in which the cranial angle was smaller than the angle used for the grouping was defined as Group A, and the group with a larger angle was defined as Group B. The Mann-Whitney $U$-test was used to compare FE angle and AR

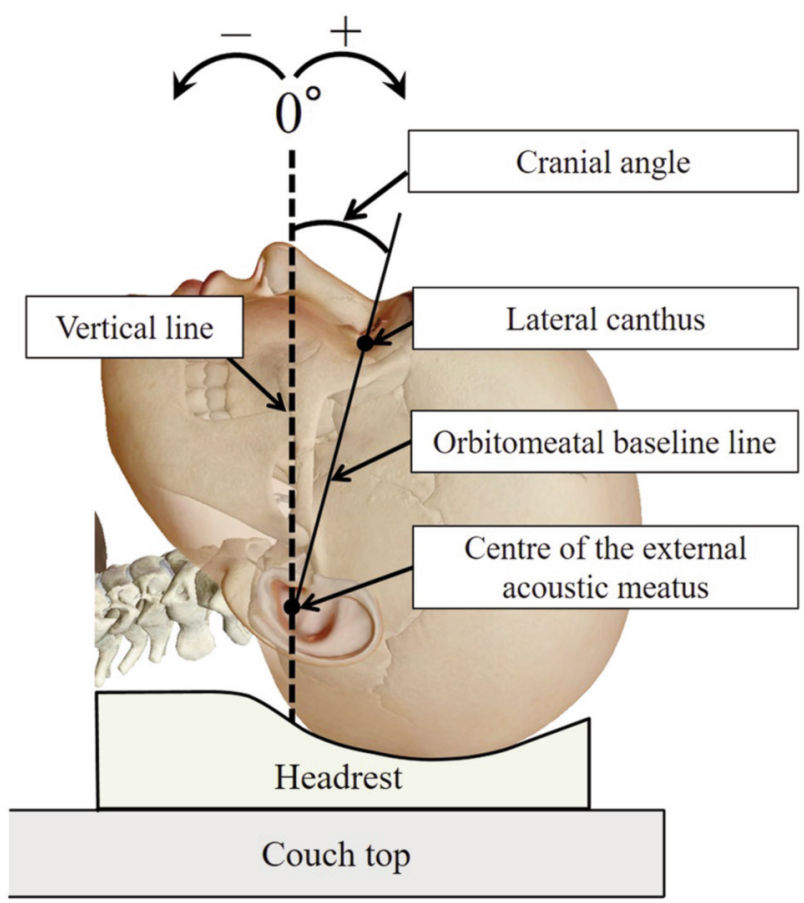

Figure 2. Illustration of the orbitomeatal baseline and cranial angle.

angle between these groups. In addition, the statistical analysis between the average value of upper cervical vertebrae (C1-C3) and lower cervical vertebrae (C5-C7) was performed by the Mann-Whitney $U$ test. Furthermore, the relationship between cranial angle and twisting angle (FE angle and AR angle) were analysed using Pearson's productmoment correlation coefficient. All statistical analyses were performed using EZR version 1.36 (15), which is a graphical user interface for $\mathrm{R}$ (The R Foundation for Statistical Computing, Vienna, Austria). Statistical significance was considered at $p<0.05$.

\section{Results}

Tables I-IV show the FE and AR angles and $p$-values of each group. In the upper cervical vertebrae (C1-C3), when the group was divided at $20^{\circ}$, there was no significant difference in twisting of cervical vertebrae, whereas when divided at $25^{\circ}$, Group A was significantly smaller than Group B in all cervical 


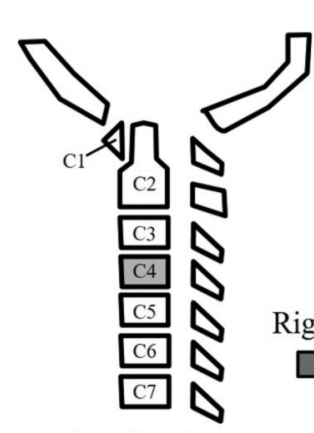

(a) planning CT

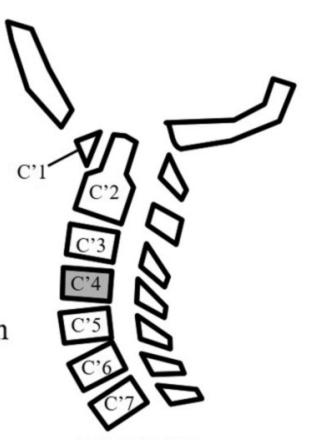

(b) MVCT

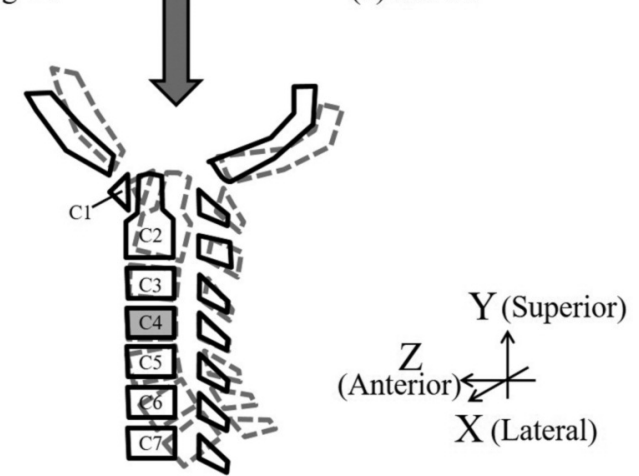

(c) planning CT and MVCT with registration

Figure 3. Illustration of the planning computed tomography (CT) and megavoltage $C T(M V C T)$ in a sagittal view. Rigid image registration was performed on the planning CT images with reference to the fourth cervical vertebra. In the lower row, the solid lines denote the planning $C T$, and the dotted lines denote the MVCT with rigid image registration.

vertebrae. When the group was divided at $30^{\circ}$ or $35^{\circ}$, the twist angle of Group A was significantly reduced in most cervical vertebrae; however, some cervical vertebrae (i.e. $30^{\circ}$, FE angle in $\mathrm{C} 3$ and $\mathrm{AR}$ angle in $\mathrm{C} 1 ; 35^{\circ}, \mathrm{FE}$ angle in $\mathrm{C} 2$ and $\mathrm{C} 3$ ) showed no significant difference. In the lower cervical vertebrae (C5-C7), only a few (i.e. $20^{\circ}, \mathrm{FE}$ angle in $\mathrm{C} 6$ and $\mathrm{AR}$ angle in $\mathrm{C} 5$ and $\mathrm{C} 6 ; 25^{\circ} \mathrm{FE}$ angle in $\mathrm{C} 5$ and $\mathrm{C} 6 ; 30^{\circ} \mathrm{FE}$ angle in $\mathrm{C} 5 ; 35^{\circ} \mathrm{FE}$ angle and $\mathrm{AR}$ angle in $\mathrm{C} 5$ ) showed significant differences between Group A and Group B; however, there was no significant difference in other cervical vertebrae.

Figures 5 and 6 show the relationship between the cranial angle and FE and AR angles of each cervical vertebra, respectively. The average values \pm standard deviation are shown in the figures. When the average values of each cervical vertebra were compared with the FE angle, only C6 $\left(3.4^{\circ} \pm 1.8^{\circ}\right)$ and $\mathrm{C} 7\left(3.2^{\circ} \pm 2.2^{\circ}\right)$ exceeded $3^{\circ}$. Meanwhile, the maximum value of the average AR angle was found at $\mathrm{C} 7$ $\left(2.5^{\circ} \pm 1.9^{\circ}\right)$. In addition, when the average values between the upper cervical vertebrae and the lower cervical vertebrae were compared, there was no significant difference in the AR angle $\left(2.3^{\circ} \pm 1.5^{\circ}\right.$ vs. $\left.2.2^{\circ} \pm 1.5^{\circ} ; p=0.70\right)$; however, in the FE angle, the value was significantly larger in the lower cervical

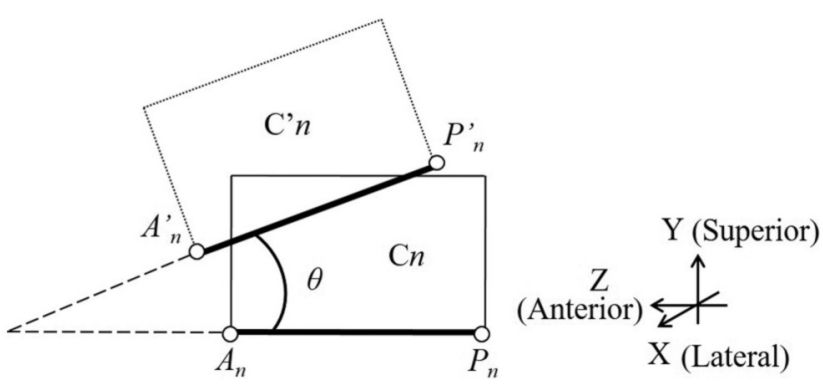

Figure 4 . In the nth cervical vertebra, the anterior centre $\left(A_{n}\right)$ and posterior centre $\left(P_{n}\right)$ of the lower end were decided. A line connecting $A_{n}$ and $P_{n}$ was defined as the reference line for measurement $\left(A_{n}-P_{n}\right)$. Angle $\theta$ was calculated between $A_{n}-P_{n}$ in planning computed tomography and $A_{n}^{\prime}{ }^{\prime}{ }_{n}^{\prime}$ in megavoltage computed tomography.

vertebra $\left(2.5^{\circ} \pm 1.8^{\circ}\right.$ vs. $\left.3.2^{\circ} \pm 1.5^{\circ} ; p=0.04\right)$. Table $\mathrm{V}$ shows Pearson's correlation coefficient for each cervical vertebra. There were weak correlations $(>0.3)$ for $\mathrm{C} 1, \mathrm{C} 2, \mathrm{C} 3, \mathrm{C} 5$, and C6, and none were strong. For both FE and AR angles, the correlation coefficient value was at a minimum in $\mathrm{C} 7$.

\section{Discussion}

In this study, we presented detailed data on the relation between cranial angle and twisting of the cervical vertebrae (FE and AR). Although the cranial angle was not strongly correlated with twisting (Table V), when the patients are divided into two groups, the twisting angle of the smaller angle group was significantly reduced (Tables I-IV). In particular, when divided at the cranial angle of $25^{\circ}$, the group less than $25^{\circ}$ significantly and efficiently reduced twisting in upper cervical vertebrae (C1-C3) over groups with larger angles. The range of twisting of the cervical vertebrae is restricted by the uncinate process of Luschka's joints (12). At a cranial angle of less than $25^{\circ}$, the cervical vertebrae flexes compared with larger cranial angles. During flexion of the cervical vertebra, the uncinate process between the upper cervical vertebra and the lower cervical vertebra joined together. Therefore, because the range of twisting was restricted by the uncinate process, the FE and AR were reduced.

In the lower cervical vertebrae (C5-C7), almost no significant difference arose for any groups. When comparing the average values of the FE and AR angles, both showed the largest error in the lower cervical vertebra (C6 in the FE angle and $\mathrm{C} 7$ in the AR angle). Moreover, when comparing the average values of the upper and lower cervical vertebrae, the value was significantly larger in the lower cervical vertebra in the FE angle. This result was consistent with other studies reporting that the set-up errors were larger in the lower cervical vertebrae than those in the upper cervical vertebrae (16). The patient set-up errors of the lower cervical vertebrae are greatly affected by weight loss and movement 
Table I. Comparison of flexion-extension (FE) angle and axial rotation $(A R)$ angle between Group A (cranial angle $<20^{\circ}$ ) and Group B (cranial angle $\geq 20^{\circ}$ ).

\begin{tabular}{|c|c|c|c|c|c|c|}
\hline \multirow{2}{*}{$\begin{array}{l}\text { Cervical } \\
\text { vertebra }\end{array}$} & \multicolumn{3}{|c|}{$\begin{array}{c}\text { FE angle }\left[{ }^{\circ}\right] \\
\text { (Average } \pm \text { standard deviation) }\end{array}$} & \multicolumn{3}{|c|}{$\begin{array}{c}\text { AR angle }\left[{ }^{\circ}\right] \\
\text { (Average } \pm \text { standard deviation) }\end{array}$} \\
\hline & Group A & Group B & $p$-Value & Group A & Group B & $p$-Value \\
\hline $\mathrm{C} 1$ & $1.0 \pm 1.2$ & $2.2 \pm 1.7$ & 0.388 & $0.8 \pm 0.3$ & $2.3 \pm 1.9$ & 0.573 \\
\hline $\mathrm{C} 2$ & $2.1 \pm 0.2$ & $3.1 \pm 2.5$ & 0.947 & $1.4 \pm 0.4$ & $2.4 \pm 1.3$ & 0.234 \\
\hline $\mathrm{C} 3$ & $2.6 \pm 1.9$ & $2.4 \pm 1.2$ & 0.842 & $2.2 \pm 0.5$ & $2.3 \pm 1.4$ & 0.947 \\
\hline C5 & $2.1 \pm 0.7$ & $3.0 \pm 1.6$ & 0.421 & $0.6 \pm 0.2$ & $2.0 \pm 0.8$ & 0.023 \\
\hline C6 & $1.0 \pm 0.7$ & $3.7 \pm 1.7$ & 0.023 & $0.1 \pm 0.1$ & $2.4 \pm 1.4$ & 0.047 \\
\hline C7 & $3.5 \pm 1.0$ & $3.2 \pm 2.3$ & 0.947 & $1.8 \pm 1.9$ & $2.6 \pm 2.0$ & 0.491 \\
\hline
\end{tabular}

Table II. Comparison of flexion-extension (FE) angle and axial rotation $(A R)$ angle between Group A (cranial angle $\left.<25^{\circ}\right)$ and Group B (cranial angle $\geq 25^{\circ}$ ).

\begin{tabular}{llllllll}
\hline & \multicolumn{3}{c}{$\begin{array}{c}\text { FE angle }\left[{ }^{\circ}\right] \\
\text { Average } \pm \text { standard deviation) }\end{array}$} & & \multicolumn{3}{c}{$\begin{array}{c}\text { AR angle }\left[{ }^{\circ}\right] \\
\text { (Average } \pm \text { standard deviation) }\end{array}$} \\
\cline { 7 - 8 } $\begin{array}{l}\text { Cervical } \\
\text { vertebra }\end{array}$ & Group A & Group B & $p$-Value & & Group A & Group B & $p$-Value \\
\hline C1 & $1.2 \pm 0.9$ & $2.9 \pm 0.9$ & 0.045 & & $1.2 \pm 1.4$ & $3.1 \pm 1.7$ & 0.028 \\
C2 & $1.5 \pm 0.8$ & $4.7 \pm 2.4$ & 0.001 & & $1.7 \pm 1.0$ & $3.0 \pm 1.0$ & 0.022 \\
C3 & $1.8 \pm 1.2$ & $3.1 \pm 1.2$ & 0.017 & & $1.5 \pm 0.8$ & $3.2 \pm 0.8$ & 0.006 \\
C5 & $2.1 \pm 1.0$ & $3.8 \pm 1.0$ & 0.013 & & $1.7 \pm 1.0$ & $2.1 \pm 0.9$ & 0.356 \\
C6 & $2.5 \pm 1.3$ & $4.4 \pm 1.2$ & 0.028 & & $1.8 \pm 1.6$ & $2.5 \pm 1.5$ & 0.315 \\
C7 & $2.8 \pm 1.7$ & $3.7 \pm 2.0$ & 0.4 & & $2.4 \pm 1.2$ & $2.7 \pm 1.9$ & 0.78 \\
\hline
\end{tabular}

Table III. Comparison of flexion-extension (FE) angle and axial rotation $(A R)$ angle between Group A (cranial angle $<30^{\circ}$ ) and Group B (cranial angle $\geq 30^{\circ}$ ).

\begin{tabular}{|c|c|c|c|c|c|c|}
\hline \multirow{2}{*}{$\begin{array}{l}\text { Cervical } \\
\text { vertebra }\end{array}$} & \multicolumn{3}{|c|}{$\begin{array}{c}\text { FE angle }\left[{ }^{\circ}\right] \\
\text { (Average } \pm \text { standard deviation) }\end{array}$} & \multicolumn{3}{|c|}{$\begin{array}{c}\text { AR angle }\left[{ }^{\circ}\right] \\
\text { (Average } \pm \text { standard deviation) }\end{array}$} \\
\hline & Group A & Group B & $p$-Value & Group A & Group B & $p$-Value \\
\hline $\mathrm{C} 1$ & $1.4 \pm 1.3$ & $3.1 \pm 1.8$ & 0.031 & $1.5 \pm 1.5$ & $3.2 \pm 1.9$ & 0.083 \\
\hline $\mathrm{C} 2$ & $1.9 \pm 1.3$ & $4.9 \pm 2.7$ & 0.017 & $1.8 \pm 0.9$ & $3.2 \pm 1.4$ & 0.036 \\
\hline $\mathrm{C} 3$ & $2.0 \pm 1.3$ & $3.1 \pm 0.9$ & 0.083 & $1.5 \pm 0.8$ & $3.7 \pm 0.6$ & $<0.001$ \\
\hline $\mathrm{C} 5$ & $2.2 \pm 1.0$ & $4.2 \pm 1.7$ & 0.01 & $1.7 \pm 0.9$ & $2.2 \pm 0.8$ & 0.227 \\
\hline C6 & $2.8 \pm 1.3$ & $4.4 \pm 2.2$ & 0.12 & $1.9 \pm 1.6$ & $2.5 \pm 1.3$ & 0.384 \\
\hline C7 & $2.9 \pm 2.0$ & $3.7 \pm 2.5$ & 0.482 & $2.2 \pm 1.8$ & $3.0 \pm 2.2$ & 0.432 \\
\hline
\end{tabular}

of the body (16-18). In this study, the difference in body weight from the first day to the last day was $-3.7 \pm 2.9 \mathrm{~kg}$ (range $=-0.1$ to -9.1$)$. However, it is assumed that the effect of body weight loss was small because only the first three fractions were used for MVCT images in the analysis. Also, even if the cranial set-up angle held in the referenced position
Table IV. Comparison of flexion-extension $(F E)$ angle and axial rotation $(A R)$ angle between Group A (cranial angle $\left.<35^{\circ}\right)$ and Group B (cranial angle $\geq 35^{\circ}$ ).

\begin{tabular}{lllllllll}
\hline & \multicolumn{3}{c}{$\begin{array}{c}\text { FE angle }\left[{ }^{\circ}\right] \\
\text { Average } \pm \text { standard deviation) }\end{array}$} & & \multicolumn{3}{c}{$\begin{array}{c}\text { AR angle }\left[{ }^{\circ}\right] \\
\text { Average } \pm \text { standard deviation) }\end{array}$} \\
\cline { 8 - 9 } $\begin{array}{l}\text { Cervical } \\
\text { vertebra }\end{array}$ & Group A & Group B & $p$-Value & & Group A & Group B & $p$-Value \\
\hline C1 & $1.5 \pm 1.2$ & $4.3 \pm 1.0$ & 0.006 & & $1.7 \pm 1.6$ & $4.1 \pm 1.0$ & 0.02 \\
C2 & $2.8 \pm 2.3$ & $3.8 \pm 2.8$ & 0.469 & & $2.0 \pm 1.1$ & $3.7 \pm 0.8$ & 0.014 \\
C3 & $2.3 \pm 1.3$ & $3.0 \pm 0.8$ & 0.411 & & $1.9 \pm 1.0$ & $4.1 \pm 0.6$ & 0.001 \\
C5 & $2.6 \pm 1.1$ & $4.6 \pm 2.1$ & 0.049 & & $1.7 \pm 0.8$ & $2.7 \pm 0.6$ & 0.037 \\
C6 & $3.4 \pm 1.6$ & $4.2 \pm 2.8$ & 0.53 & & $2.0 \pm 1.5$ & $2.9 \pm 1.0$ & 0.262 \\
C7 & $2.8 \pm 2.2$ & $4.4 \pm 2.2$ & 0.307 & & $2.3 \pm 1.8$ & $3.7 \pm 2.2$ & 0.221 \\
\hline
\end{tabular}

Table V. Pearson's correlation coefficient between the cranial angle and twisting for each cervical vertebra.

\begin{tabular}{lcc}
\hline Cervical vertebra & FE angle & AR angle \\
\hline C1 & 0.67 & 0.61 \\
C2 & 0.51 & 0.57 \\
C3 & 0.36 & 0.67 \\
C5 & 0.58 & 0.5 \\
C6 & 0.55 & 0.49 \\
C7 & 0.15 & 0.24 \\
\hline
\end{tabular}

using the thermoplastic mask, body movements would be able to cause the lower cervical vertebrae to shift $(16,17)$. Thus, because it was difficult to suppress the twisting of the lower cervical vertebrae using only the thermoplastic mask, systematic errors unrelated to the cranial set-up angle were increased. Indeed, the correlation coefficient value between twisting and the cranial angle was minimal in C7 (Table V). Thus, no significant differences were observed in the lower cervical vertebrae.

In this study, it was shown that FE and AR angles of the upper cervical vertebrae could be reduced by positioning the cranial angle at $>25^{\circ}$. However, when divided into two groups at $20^{\circ}$, no significant difference was observed in most cervical vertebrae. Fewer patients had a cranial angle $>20^{\circ}$ when Silverman's headrest type B or C were used at our facility; therefore, it is considered that no significant difference was observed due to statistical uncertainty. By contrast, Lam et al. (10) have indicated that an extended neck position (approximately $20^{\circ}$ cranial angle) reduces the translational set-up error more so than a flexed position (approximately $10^{\circ}$ ). Based on these results, the optimal cranial angle to reduce the set-up error of cervical vertebrae in head and neck radiotherapy is between $20^{\circ}$ and $25^{\circ}$.

In conclusion, we studied the relationship between cervical vertebrae twisting and the cranial angle during 

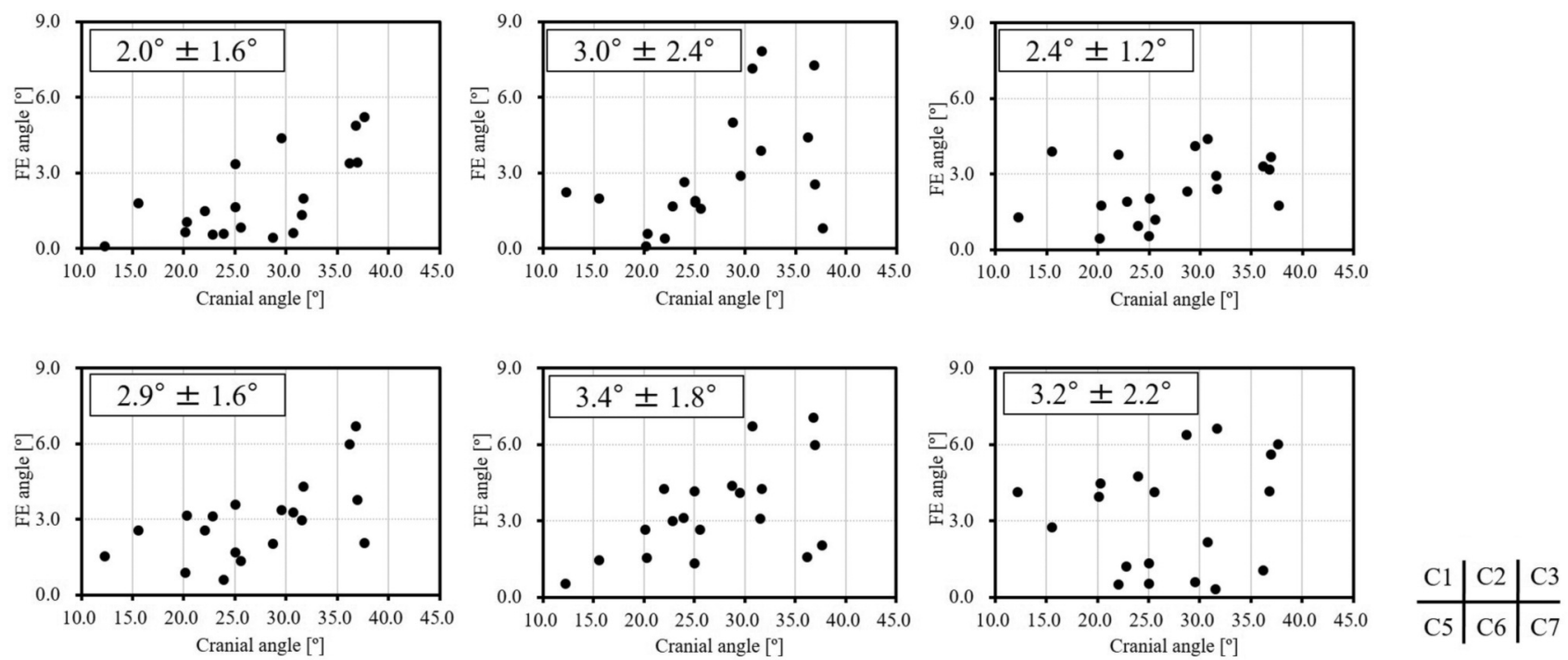

Figure 5. The relationship between the cranial angle during planning computed tomography and flexion-extension (FE) angle. The average values \pm standard deviation are shown.
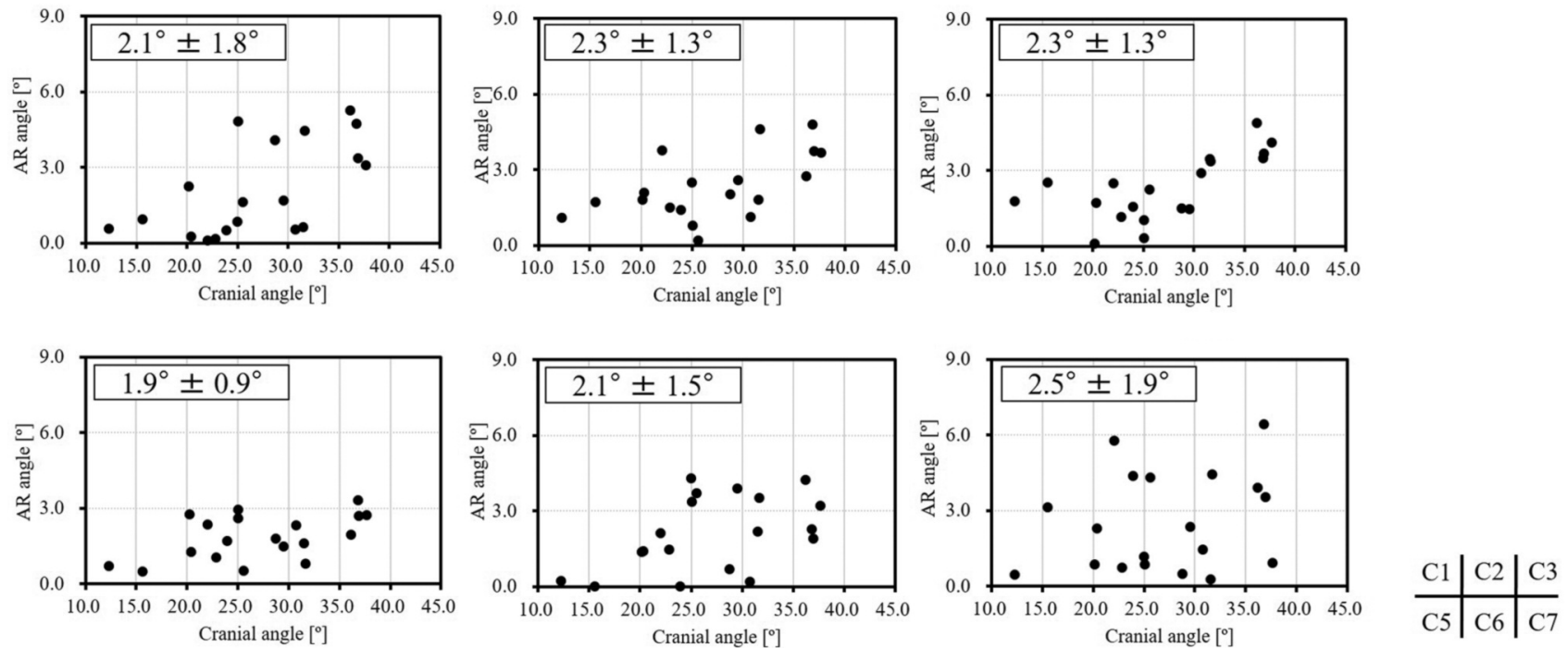

Figure 6. The relationship between the cranial angle during planning computed tomography and axial rotation (AR) angle. The average values \pm standard deviation are shown.

planning CT in head and neck radiotherapy. Although the cranial angle was not strongly correlated with the twisting angle, we found that positioning patients at a cranial angle of less than $25^{\circ}$ significantly reduced the set-up error of twisting in the upper cervical vertebrae (C1-C3). In the lower cervical vertebrae (C5-C7), however, there was almost no significant difference in any group. Because the cranial angle of $20^{\circ}$ reduced the translational set-up error in a previous study, the optimal cranial angle to reduce the set-up error of cervical vertebrae is between $20^{\circ}$ and $25^{\circ}$.

\section{Conflicts of Interest}

No Authors have any conflicts of interest to declare regarding this study.

\section{Authors' Contributions}

Each Author contributed as follows: study conception and design, Takahiro Aoyama, Hidetoshi Shimizu, Mio Ando, Naoki Kaneda; analysis and interpretation of data, Takahiro Aoyama, Hidetoshi Shimizu, Koji Sasaki; drafting of manuscript, Takahiro Aoyama, 
Hidetoshi Shimizu, Koji Sasaki; supporting experiment and editing the article, Naoki Kaneda, Hiroyuki Tachibana, Kojiro Suzuki, Takeshi Kodaira.

\section{Acknowledgements}

The Authors are grateful to the staff at all cooperating facilities and Mr. Tadashi Nakabayashi of RaySearch Japan K.K. and Mr. Kentaro Sugi of Hitachi, Ltd. for useful discussions. Furthermore, the Authors would like to thank Enago (www.enago.jp) for the English language review.

\section{References}

1 Mackie TR, Holmes T, Swerdloff S, Reckwerdt P, Deasy JO, Yang J, Paliwal B and Kinsella T: Tomotherapy: A new concept for the delivery of dynamic conformal radiotherapy. Med Phys 20(6): 1709-1719, 1993. PMID: 8309444. DOI: 10.1118/1.596958

2 Burman C, Chui CS, Kutcher G, Leibel S, Zelefsky M, LoSasso T, Spirou S, Wu Q, Yang J, Stein J, Mohan R, Fuks Z and Ling CC: Planning, delivery, and quality assurance of intensity-modulated radiotherapy using dynamic multileaf collimator: A strategy for large-scale implementation for the treatment of carcinoma of the prostate. Int J Radiat Oncol Biol Phys 39(4): 863-873, 1997. PMID: 9369136. DOI: 10.1016/s0360-3016(97)00458-6

3 Kam MK, Leung SF, Zee B, Chau RM, Suen JJ, Mo F, Lai M, Ho R, Cheung KY, Yu BK, Chiu SK, Choi PH, Teo PM, Kwan WH and Chan AT: Prospective randomized study of intensity-modulated radiotherapy on salivary gland function in early-stage nasopharyngeal carcinoma patients. J Clin Oncol 25(31): 4873-4879, 2007. PMID: 17971582. DOI: 10.1200/JCO. 2007.11.5501

4 Lee N, Xia P, Quivey JM, Sultanem K, Poon I, Akazawa C, Akazawa $\mathrm{P}$, Weinberg $\mathrm{V}$ and $\mathrm{Fu} \mathrm{KK}$ : Intensity-modulated radiotherapy in the treatment of nasopharyngeal carcinoma: an update of the UCSF experience. Int J Radiat Oncol Biol Phys 53(1): 12-22, 2002. PMID: 12007936. DOI: 10.1016/s03603016(02)02724-4

5 Yu Y, Michaud AL, Sreeraman R, Liu T, Purdy JA and Chen AM: Comparison of daily versus nondaily image-guided radiotherapy protocols for patients treated with intensity-modulated radiotherapy for head and neck cancer. Head neck 36(7): 992-997, 2014. PMID: 23780718. DOI: 10.1002/hed.23401

6 Ma J, Chang Z, Wang Z, Wu QJ, Kirkpatrick JP and Yin FF: ExacTrac X-ray 6 degree-of-freedom image-guidance for intracranial non-invasive stereotactic radiotherapy: comparison with kilo-voltage cone-beam CT. Radiother Oncol 93(3): 602-608, 2009. PMID: 19846229. DOI: 10.1016/j.radonc.2009.09.009

7 Chang Z, Wang Z, Ma J, O'Daniel JC, Kirkpatrick JP and Yin FF: 6D image guidance for spinal non-invasive stereotactic body radiation therapy: Comparison between ExacTrac X-ray 6D with kilo-voltage cone-beam CT. Radiother Oncol 95(1): 116-121, 2010. PMID: 20122747. DOI: 10.1016/j.radonc.2009.12.036

8 Ostyn M, Dwyer T, Miller M, King P, Sacks R, Cruikshank R, Rosario M, Martinez D, Kim S and Yeo WH: An electromechanical, patient positioning system for head and neck radiotherapy. Phys Med Biol 62(18): 7520-7531, 2017. PMID 28816703. DOI: 10.1088/1361-6560/aa86e3
9 Shimizu H, Sasaki K, Aoyama T, Matsushima S, Isomura T, Fukuma H, Tachibana $\mathrm{H}$ and Kodaira T: Development of twistcorrection system for radiotherapy of head and neck cancer patients. J Appl Clin Med Phys 20(7): 128-134, 2019. PMID: 31222881. DOI: $10.1002 / \mathrm{acm} 2.12667$

10 Lam JC, Wu VW, Chiu G, Kong PS and Wong CM: A comparison of dose and set-up accuracy between flexed and extended neck positions in helical tomotherapy of nasopharyngeal carcinoma. Med Dosim 22, 2020. PMID: 31982242. DOI: 10.1016/j.meddos.2019.12.005

11 Panjabi MM, Oda T, Crisco III JJ, Dvorak J and Grob D: Posture affects motion coupling patterns of the upper cervical spine. J Orthop Res 11(4): 525-536, 1993. PMID: 8340825. DOI: 10.1002/jor.1100110407

12 Kapandji AI: Anatomie Fonctionnelle. Tome III. 6e éd. Paris, Éditions Maloine; 2005

13 Leech M, Coffey M, Mast M, Moura F, Osztavics A, Pasini D and Vaandering A: ESTRO ACROP guidelines for positioning, immobilisation and position verification of head and neck patients for radiation therapists. Tech Innov Patient Support Radiat Oncol 5(1): 1-7, 2017. PMID: 32095536. DOI: 10.1016/ j.tipsro.2016.12.001

14 Barker JL Jr, Garden AS, Ang KK, O'Daniel JC, Wang H, Court LE, Morrison WH, Rosenthal DI, Chao KS, Tucker SL, Mohan R and Dong L: Quantification of volumetric and geometric changes occurring during fractionated radiotherapy for head-and-neck cancer using an integrated CT/linear accelerator system. Int J Radiat Oncol Biol Phys 59(4): 960-970, 2004. PMID: 15234029. DOI: 10.1016/j.ijrobp.2003.12.024

15 Kanda Y: Investigation of the freely available easy-to-use software "EZR" for medical statistics. Bone Marrow Transplant 48(3): 452458, 2013. PMID: 23208313. DOI: 10.1038/bmt.2012.244

16 van Kranen S, van Beek S, Rasch C, van Herk M and Sonke JJ: Setup uncertainties of anatomical sub-regions in head-and-neck cancer patients after offline CBCT guidance. Int J Radiat Oncol Biol Phys 73(5): 1566-1573, 2009. PMID: 19306753. DOI: 10.1016/j.ijrobp.2008.11.035,

17 Rotondo RL, Sultanem K, Lavoie L, Skelly J and Raymond L: Comparison of repositioning accuracy of two commercially available immobilization systems for computed tomography imaging. Int J Radiat Oncol Biol Phys 70(5): 1389-1396, 2008. PMID: 18207659. DOI: 10.1016/j.ijrobp.2007.08.035

18 Lees J: Incidence of weight loss in head and neck cancer patients on commencing radiotherapy treatment at a regional oncology centre. Eur J Cancer Care 8(3): 133-136, 1999. PMID: 10763643. DOI: 10.1046/j.1365-2354.1999.00156.x

Received May 1, 2020

Revised May 13, 2020

Accepted May 14, 2020 